\title{
A STUDY ON VEGETATIVE PROPAGATION OF Huperzia serrata BY CUTTINGS IN SA PA, LAO CAI
}

\author{
Le Thi Lan Anh ${ }^{1}$, Bui Tuan Anh ${ }^{3}$, Giang Xuan Sang ${ }^{3}$, Ton That Huu Dat ${ }^{4}$, \\ Ho Thi Huong ${ }^{2}$, Nguyen Duc Thanh ${ }^{1,2, *}$, Le Thi Bich Thuy ${ }^{1,2}$ \\ ${ }^{1}$ Graduate University of Science and Technology, VAST, Vietnam \\ ${ }^{2}$ Institute of Biotechnology, VAST, Vietnam \\ ${ }^{3}$ Hoang Lien National Park, Lai Chau, Vietnam \\ ${ }^{4}$ Mientrung Institute for Scientific Research, VAST, Vietnam
}

Received 8 July 2019, accepted 16 August 2019

\begin{abstract}
Huperzia serrata is a precious medicinal plant used in medicine to support and treat Alzheimer's disease. Currently, this species is in danger of extinction due to indiscriminate exploitation for commercial purposes. Furthermore, this species reproduces slowly and is difficult to cultivate artificially. The reproduction by spores of this species is very long and takes 15-20 years from the spore germination to mature plant, whereas asexual reproduction by tissue culture is also difficult. Therefore, cutting is an effective method to propagate this species on a large scale. In this study, we surveyed the factors affecting the survival rate, the rooting and the number of new leaves of the stem cuttings, including cutting length, growing substrate, and effects of growthregulating hormones IBA (0 ppm, 500 ppm, 1000 ppm, 2000 ppm and 3000 ppm) and $\alpha$-NAA (0 ppm, $10 \mathrm{ppm}, 20 \mathrm{ppm}, 30 \mathrm{ppm}$ and $40 \mathrm{ppm}$ ). The experimental results showed that using cuttings of $6 \mathrm{~cm}$ in length treated with IBA at a concentration of $1000 \mathrm{ppm}$ for 30 mins and cultured on the substrate mixture of soil, decomposed animal manure and rice husk at a ratio of 3:1:1 was the best for cuttings of $H$. serrata in $\mathrm{Sa} \mathrm{Pa}$. The results of this study will contribute to the conservation and development of genetic source of $H$. serrata in Vietnam.
\end{abstract}

Keywords: $H$. serrata, cutting, IBA, regulating hormones, NAA, propagation.

Citation: Le Thi Lan Anh, Bui Tuan Anh, Giang Xuan Sang, Ton That Huu Dat, Ho Thi Huong, Nguyen Duc Thanh, Le Thi Bich Thuy, 2019. A study on vegetative propagation of Huperzia serrata by cuttings in Sa Pa, Lao Cai. Academia Journal of Biology, 41(3): 107-113. https://doi.org/10.15625/2615-9023/v41n3.13921.

*Corresponding author email: nguyenducthanh_pcg@ibt.ac.vn

(O2019 Vietnam Academy of Science and Technology (VAST) 


\section{INTRODUCTION}

$H$. serrata is a precious medicinal plant in the red list of the Program of research on conservation and development of rare and precious gene sources for medicinal plants (Nong Van Duy, 2015). This plant has many medical effects, especially dementia (Alzheimer) of the elderly. At present, this plant is being indiscriminately procured and exploited, leading to a decline in this precious medicinal resource in nature. Hence, studies on $H$. serrata are receiving the concern of many countries in the world, including Vietnam.

The reproduction of $H$. serrata is a combination of sexual and asexual reproduction (Whittier et al., 2007). Similar to other species of genera Huperzia and Lycopodium, the spore germination process of $H$. serrata is poor under controlled conditions. The gametophytes and sporophytes of this species are often long-lived and grow slowly in an environment having high relative humidity and abundant organic matter; therefore, it is difficult to propagate (Ma et al., 2006). Studies show that spores of species belonging to the genus Huperzia take 2-5 years to develop into sporophytes (Whitter et al., 2007). This development process in $H$. serrata is much slower and usually requires 15-20 years of growth since spore germination to maturity (Ferreira et al., 2016). Thus, the spore germination methods of $H$. serrata in soil environment or sterile culture media are not-yet performed. Although vegetative propagation of $H$. serrata by tissue culture has been successful in the world, it is difficult to obtain large biomass and requires a long time (Ma et al., 2008; Ma et al., 2015; Manpreet et al., 2016). Moreover, the process of transferring tissue culture plants to natural habitats is difficult; therefore, the propagation by cuttings is a suitable option for rapid propagation of this plant.

In Vietnam, $H$. serrata is scattered in the midland provinces and high mountains in North West and Central Hight Land; however, this precious genetic resource is being lost. Until now, there have been only surveys on distribution areas and growth of this plant (Nguyen Quang Hieu et al., 2017), but there have not been any specific studies on the propagation of this plant in natural conditions. Therefore, we investigated the effect of several factors (substrate, cutting length, growth-regulating hormones) on propagating this plant by cuttings.

\section{MATERIALS AND METHODS}

The samples of $H$. serrata used in the present study were healthy and not infected with pests and diseases, evenly sized, and branched. The plant samples were collected at $\mathrm{Ta}$ Phin forest, $\mathrm{Sa} \mathrm{Pa}$. The study was conducted in $\mathrm{Sa} \mathrm{Pa}$ from April 2015 to November 2016.

Plant materials were identified following Nong Van Duy (2015). The stem cuttings were collected on 7:00 - 9:00 am, the lower of cuttings was bevel cut to increase the contact area of cuttings to soil and enhance the growth of roots.

The nursery was designed in the forest (Figure 1d). The cuttings were treated with IBA and $\alpha$-NAA, and then immediately plugged into the substrate (Hoang Minh Tan, 1993).

The experiments were designed into complete randomized blocks in triplicate. Each experiment included 120 cuttings with a potting soil size of $8 \mathrm{~cm} \times 10 \mathrm{~cm}$ per replication.

Three experiments were designed from 1 to 3 respectively and each of the following experiments was designed based on the results of the previous experiment.

Experiment 1: study on each of the length of cuttings from $4 \mathrm{~cm}$ to $10 \mathrm{~cm}$ (Fig. 1a).

Experiment 2: using 4 substrate mixtures of forest soil: decomposed animal manure: rice husk: vermicompost with ratios as follows: CT1 ratio: 3: 1: 0: 0; CT2 ratio: 3: 1: 1: 0; CT3 ratio: 3: 1: 1: 1; CT4 ratio: 3: 0: 1: 1 (Fig. 1b).

Experiment 3: cuttings were treated with $\alpha$ - NAA at concentrations of $0 \mathrm{ppm}, 10 \mathrm{ppm}$, $20 \mathrm{ppm}, 30 \mathrm{ppm}$ and $40 \mathrm{ppm}$ for 5 mins, and 
with IBA at concentrations of $0 \mathrm{ppm}, 500$ ppm; $1000 \mathrm{ppm}, 2000 \mathrm{ppm}$ and $3000 \mathrm{ppm}$ for 30 mins (Fig. 1c).

Monitoring parameters: survival rate (\%); rooting rate $(\%)$; rate of cutting with new leaves (\%); number of new leaves; number of roots. Each experiment was monitored for 4 months since cuttings were planted into the substrate (Fig. 1d).

Experimental data were processed by Microsoft Excel 2007 and IRRISTAT version 5.0.

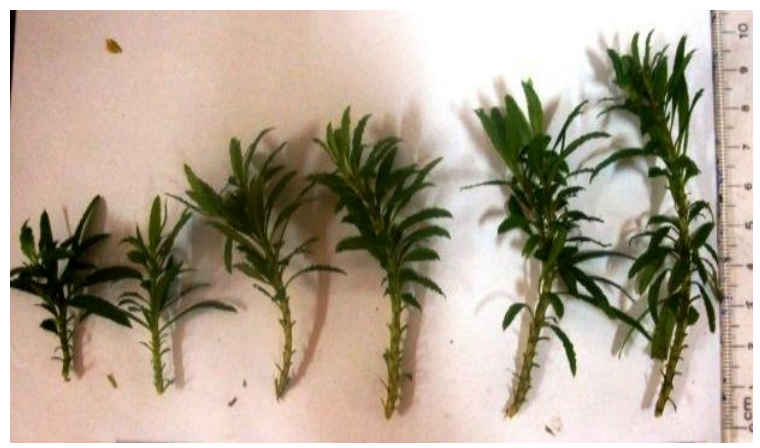

a

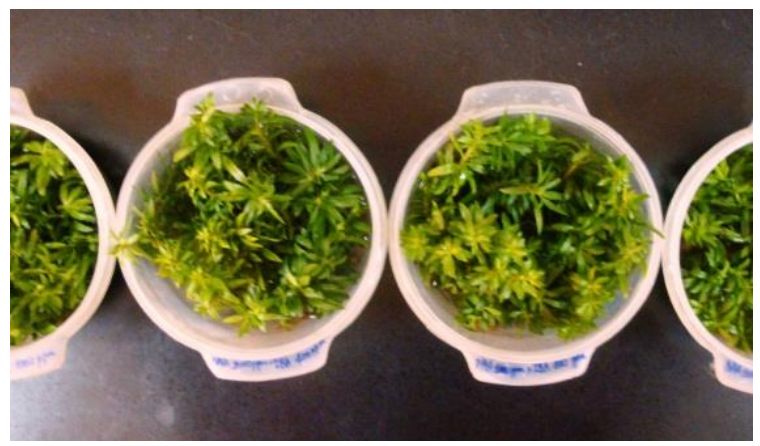

c

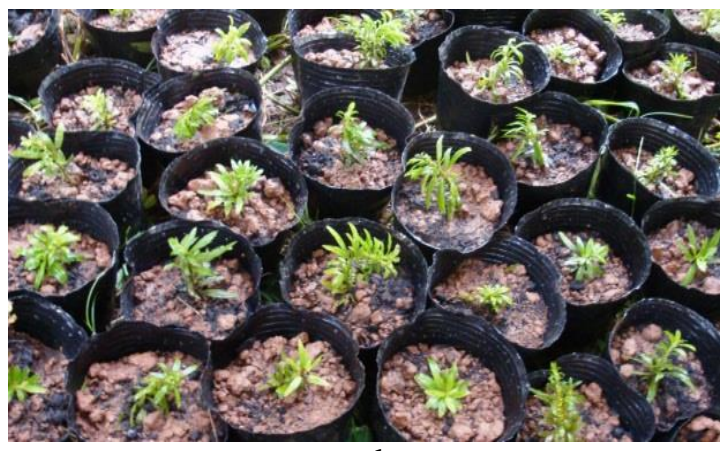

b

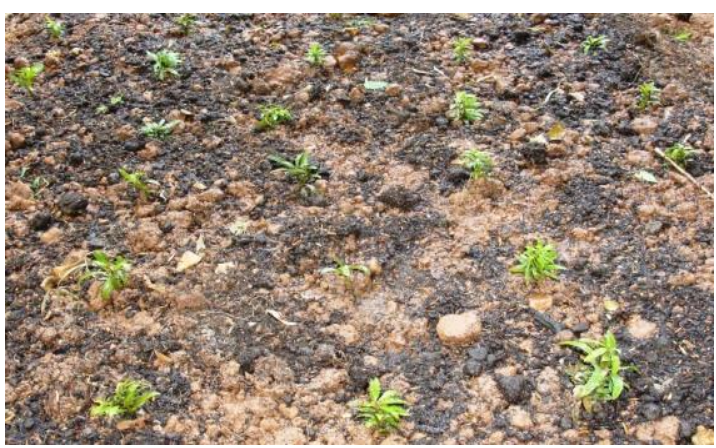

d

Figure 1. Vegetative propagation of Huperzia serrate by cutting: a. Cuttings with different lengths used in vegetative propagation of Huperzia serrata; b. Huperzia serrata was planted on the CT2 substrates; c. Cuttings were treated with growth-regulating hormones IBA and $\alpha$-NAA; d. The nursery of Huperzia serrate

\section{RESULTS AND DISCUSSION}

Effect of cutting length on survival rate, rooting and growth of new leaves of $H$. serrata

In the original ecological environment, the cuttings of $H$. serrata grew easily and healthy. After 4 experimental months, the height of the cuttings almost unchanged but a few new leaves were grown. We found that the cutting length affected the growth of $H$. serrata. Experimental results are presented in table 1.

The results showed that the use of the cuttings of $4 \mathrm{~cm}$ and $5 \mathrm{~cm}$ in lengths had significantly lower survival, rooting and the rate of cutting with new leaves than the cuttings with longer lengths. The cuttings of 7 $\mathrm{cm}$ in length showed the highest survival rate of $88.33 \%$ and not significantly different compared with the survival rate of the cuttings with the length of $6 \mathrm{~cm}$ to $10 \mathrm{~cm}$. Thus, the use of the cuttings with the length of $6 \mathrm{~cm}$ would save the number of $H$. serrata used but still gave a high survival rate $(86.39 \%)$. Moreover, the cuttings of $6 \mathrm{~cm}$ in length showed highest rooting rate $(23.47 \%)$ and the rate of cutting with new leaves $(68.49 \%)$, and significantly differed from the cuttings of 
other lengths at the statistical significance of $95 \%$ and high reliability of $2.3 \%$ and $2.4 \%$, respectively. These results revealed that the use of the cuttings of $6 \mathrm{~cm}$ in length gave the best efficiency for the propagation of $H$. serrata. This result is consistent with the previous study described by Long et al.
(2014). Authors propagated $H$. serrata by cuttings method in the Yantuozhai region's forest farm and showed that the cuttings of 6 $\mathrm{cm}$ in length gave the best efficiency. Therefore, the cuttings with the length of $6 \mathrm{~cm}$ were used for further experiments.

Table 1. Effect of cutting length on the growth of $H$. serrata after 4 months

\begin{tabular}{|c|c|c|c|}
\hline Cutting length & Survival rate $(\%)$ & Rooting rate $(\%)$ & Rate of cuttings with new leaves (\%) \\
\hline $4 \mathrm{~cm}$ & $74.72^{\mathrm{c}}$ & $10.04^{\mathrm{e}}$ & $32.74^{\mathrm{d}}$ \\
\hline $5 \mathrm{~cm}$ & $78.06^{\mathrm{b}}$ & $17.79^{\mathrm{d}}$ & $47.71^{\mathrm{c}}$ \\
\hline $6 \mathrm{~cm}$ & $86.39^{\mathrm{a}}$ & $23.47^{\mathrm{a}}$ & $68.49^{\mathrm{a}}$ \\
\hline $7 \mathrm{~cm}$ & $88.33^{\mathrm{a}}$ & $21.39^{\mathrm{c}}$ & $65.41^{\mathrm{b}}$ \\
\hline $8 \mathrm{~cm}$ & $86.94^{\mathrm{a}}$ & $22.36^{\mathrm{b}}$ & $67.73^{\mathrm{ab}}$ \\
\hline $9 \mathrm{~cm}$ & $87.22^{\mathrm{a}}$ & $21.98^{\mathrm{bc}}$ & $65.29^{\mathrm{b}}$ \\
\hline $10 \mathrm{~cm}$ & $86.62^{\mathrm{a}}$ & $21.47^{\mathrm{c}}$ & $67.64^{\mathrm{ab}}$ \\
\hline CV \% & $1.5 \%$ & $2.3 \%$ & $2.4 \%$ \\
\hline $5 \%$ LSD & 2.284 & 0.799 & 2.55 \\
\hline
\end{tabular}

Note: The different letters in a column indicated significantly difference at $P<0.05$.

\section{Effect of substrates on the propagation of H. serrata}

According to Ninh Thi Phip (2013), planting substrates have a great influence on the ability to propagate plants. In propagation by cuttings, the substrates have the function of holding the cuttings in fixed positions and provide sources of water and nutrients for the cuttings. Furthermore, the substrates allow air to penetrate the base of cuttings. A good substrate must have sufficient porosity, good aeration, water retention and drainage capacity, no pests and weeds. The previous studies have shown that the most favorite environment for cuttings of $H$. serrata is the ecological forest environment (Zhang et al., 2009; Long et al., 2014). Therefore, in this study, we used forest soil as the main substrate and supplemented with manure, rice husk and vermicompost at different ratios to find the best substrate mixture for cuttings of $H$. serrata. At the same time, on the basis of previous experiment result, the cuttings of 6 $\mathrm{cm}$ in length were used. The experimental results are presented in table 2 .
The growth parameters of the cuttings using substrate mixtures supplemented with manure were higher than those of the control substrate. This suggests that increasing the porosity and nutrients of the substrates can enhance the growth ability of $H$. serrata. The survival rate of substrate mixtures CT2 $(88.89 \%)$ and CT3 $(89.72 \%)$ were significantly higher than that of other substrate mixtures. Although the survival rate of CT3 was higher than that of CT2, this difference was not statistically significant. Moreover, rooting rate $(29.07 \%)$ and rate of cuttings with new leaves $(83.44 \%)$ of CT2 substrate mixture were significantly higher than those of other substrate mixtures. It was observed that rooting rate was positively correlated to the rate of cuttings with new leaves, indicating a two-way relationship between root and leaf growth. The root growth supported for taking nutrients and water from the habitat to the plant and enhanced the growth of leaves. At the same time, the growth of leaves helped the plant grow and synthesize vegetative nutrients and promoted root growth. The CT2 mixture with 
a combination of forest soil, decomposed animal manure and rice husk that made the substrates soft, nutritious, and moist shows the most favorable for cuttings of $H$. serrata.

Table 2. Effect of substrates on the growth of $H$. serrata cuttings after 4 months

\begin{tabular}{|l|c|c|c|}
\hline \multicolumn{1}{|c|}{ Substrate mixture } & $\begin{array}{c}\text { Survival rate } \\
(\%)\end{array}$ & $\begin{array}{c}\text { Rooting rate } \\
(\%)\end{array}$ & $\begin{array}{c}\text { Rate of cuttings with new } \\
\text { leaves (\%) }\end{array}$ \\
\hline Control (forest soil) & $86.39^{\mathrm{b}}$ & $23,47^{\mathrm{c}}$ & $68.49^{\mathrm{cd}}$ \\
\hline CT1 & $87.5^{\mathrm{b}}$ & $25.71^{\mathrm{b}}$ & $69.85^{\mathrm{c}}$ \\
\hline CT2 & $88.89^{\mathrm{a}}$ & $29.07^{\mathrm{a}}$ & $83.44^{\mathrm{a}}$ \\
\hline CT3 & $89.72^{\mathrm{a}}$ & $24.77^{\mathrm{b}}$ & $70.90^{\mathrm{b}}$ \\
\hline CT4 & $86.94^{\mathrm{b}}$ & $24.92^{\mathrm{b}}$ & $67.41^{\mathrm{d}}$ \\
\hline CV\% & 0.7 & 3.2 & 1.6 \\
\hline 5\% LSD & 1.18 & 1.552 & 2.187 \\
\hline
\end{tabular}

Note: The different letters in a column indicated significantly difference at $P<0.05$.

Effect of the growth-regulating hormones IBA and $\alpha$-NAA on the growth of $H$. serrata cuttings

The addition of growth-regulating hormones plays an important role in increasing survival, root and shoot growth rates. Ninh Thi Phip (2013) suggested that using auxin to stimulate the growth of cutting root would improve the rate of plant growth. The effective auxin concentration used for herbaceous and softwood was less than 1000 ppm, and for half-hard woody plants was $2000-3000 \mathrm{ppm}$. On the other hand, Zhang et al. (2009) reported that IBA concentration of $2000 \mathrm{ppm}$ gave the best effect for $H$. serrata cuttings. According to Qin et al. (2010), shoots of $H$. serrata before cuttings were soaked in IBA solution of $1000 \mathrm{ppm}$ for 30 mins gave a high survival rate up to $93-98 \%$ and rooting rate reached $98 \%$. In addition, Long et al. (2014) using $H$. serrata cuttings of $6 \mathrm{~cm}$ length soaked in $\alpha$-NAA solution of 20 ppm for 5 mins gave a high survival rate up to $90 \%$ and rootlets of cuttings appeared only after 60 days of planting. In this study, we used cuttings of $6 \mathrm{~cm}$ in length treated with two growth-regulating hormones IBA and $\alpha$ NAA with different concentrations and treating times, then planted in the CT2 substrate. The experimental results are presented in table 3 .
The experimental results showed that $H$. serrata grew better in the forest soil environment; therefore, the growth of roots and new leaves of the cuttings were also observed when no growth-regulating hormones added. However, when IBA was used, number of roots and new leaves significantly increased. Especially, number of roots $(2.38 \pm 0.06)$ and new leaves $(2.61 \pm$ 0.06 ) of the cuttings were the best when the cuttings were treated with IBA at a concentration of $1000 \mathrm{ppm}$. At a concentration of $2000 \mathrm{ppm}$, number of roots $(2.07 \pm 0.05)$ and new leaves $(2.43 \pm 0.07)$ significantly decreased. As a consequence, treatment of the cuttings with IBA at a concentration of $1000 \mathrm{ppm}$ for $30 \mathrm{mins}$ before cutting was most suitable.

For the cuttings treated with $\alpha$-NAA, the growth of cuttings significantly increased compared to the cuttings without treatment of $\alpha$-NAA. In particular, cuttings treated with $\alpha$ NAA at a concentration of $20 \mathrm{ppm}$ for $5 \mathrm{mins}$ gave the highest number of roots $(1.97 \pm 0.06)$ and new leaves $(2.33 \pm 0.07)$. However, when comparing the promoting efficiency of $\alpha$ NAA and IBA on the growth of $H$. serrata roots and leaves, $\alpha$-NAA was less effective than IBA. Therefore, the treatment of cuttings with IBA at a concentration of $1000 \mathrm{ppm}$ for 30 mins was proven to be the best for $H$. serrata cutting propagation. 
Table 3. Effect of the growth-regulating hormones IBA and $\alpha-\mathrm{NAA}$ on the growth of $H$. serrata cuttings after 4 months

\begin{tabular}{|l|c|c|c|}
\hline Hormones & Concentration $(\mathrm{ppm})$ & Number of roots & Number of new leaves \\
\hline \multirow{4}{*}{ IBA } & 0 (water) & $1.36 \pm 0.05^{\mathrm{a}}$ & $1.58 \pm 0.08^{\mathrm{a}}$ \\
\cline { 2 - 4 } & 500 & $1.42 \pm 0.05^{\mathrm{b}}$ & $1.64 \pm 0.08^{\mathrm{b}}$ \\
\cline { 2 - 4 } & 1,000 & $2.38 \pm 0.06^{\mathrm{d}}$ & $2.61 \pm 0.06^{\mathrm{d}}$ \\
\cline { 2 - 4 } & 2,000 & $2.07 \pm 0.05^{\mathrm{e}}$ & $2.43 \pm 0.07^{\mathrm{e}}$ \\
\hline \multirow{4}{*}{ CV\% } & 3,000 & $1.97 \pm 0.06^{\mathrm{c}}$ & $2.18 \pm 0.09^{\mathrm{c}}$ \\
\hline $5 \%$ LSD & & 1.9 & 1.4 \\
\hline \multirow{5}{*}{$\alpha-\mathrm{NAA}$} & $0($ water $)$ & $1.49 \pm 0.05^{\mathrm{a}}$ & 0.0430 \\
\cline { 2 - 4 } & 10 & $1.69 \pm 0.06^{\mathrm{c}}$ & $2.98 \pm 0.08^{\mathrm{a}}$ \\
\cline { 2 - 4 } & 20 & $1.97 \pm 0.06^{\mathrm{d}}$ & $2.33 \pm 0.07^{\mathrm{c}}$ \\
\cline { 2 - 4 } & 30 & $1.91 \pm 0.06^{\mathrm{e}}$ & $2.29 \pm 0.08^{\mathrm{c}}$ \\
\hline CV\% & 40 & $1.8 \pm 0.07^{\mathrm{b}}$ & $2.19 \pm 0.08^{\mathrm{b}}$ \\
\hline $5 \%$ LSD & & 1.5 & 2.2 \\
\hline
\end{tabular}

Note: the different letters in a column indicated significantly difference at $P<0.05$.

\section{CONCLUSIONS}

The results of our study showed that the cuttings of $6 \mathrm{~cm}$ in length treated with IBA at a concentration of $1,000 \mathrm{ppm}$ for $30 \mathrm{mins}$ and the substrate mixture of soil, decomposed animal manure and rice husk at a ratio of 3:1:1 are the best materials for vegetative propagation of $H$. serrata by cutting in $\mathrm{Sa} \mathrm{Pa}$. The results of this study will contribute to the conservation and development of genetic source of $H$. serrata in Vietnam.

Acknowledgements: The work was funded by the project supported by program on conservation and sustainable use of genetic resources of Ministry of Science and Technology: "Exploitation and development of genetic resources of Huperzia serrata (Thunb) Trev in Sa Pa and Da Lat".

\section{REFERENCES}

Ferreira A., Rodrigues M., Fortuna A., Falcao A., Alves G. (2016). Huperzine A from Huperzia serrata: a review of its sources, chemistry, pharmacology and toxicology. Phytochemistry Review, 15(1): 51-58.
Hoang Minh Tan, Nguyen Quang Thach, 1993. Plant growth-promoting hormones. Agricultural Publisher, pp. 11-17.

Long H., Li Q., Li L., Huang L.H., 2014. Study on cutting and gemmae propagation of Huperzia serrata. Journal of Chinese medicinal materials. 7(7): 1115-1121.

Ma X., Gang D.R., 2008. In vitro production of Huperzine A, a promising drug candidate for Alzheimer's disease. Phytochemistry, 69 (10): 2022- 2028.

Ma X., Tan C., Zhu D., Gang D. R., 2006. A survey of potential Huperzine A natural resources in China: the Huperziaceae. J. of Ethnopharmacol, 104(1-2): 54-67.

Ma Y.Z., Liu J.H., Xu H., Liu F., 2015. In vitro cultural of Huperzia serrata. Plant Physiology Journal, 51(4): 465-470.

Manpreet K., Singh P., Kaur J., 2016. A Systematic review on Huperzia serrata. International Journal of Pharmacognosy and Phytochemical Research, 8(8): 1250-1255.

Nguyen Quang Hieu, Nguyen Thanh Tung, $\mathrm{Vu}$ Thu Thuy, Nguyen Viet Than, 2017. 
Study on the botanical characteristics of two species of Huperzia (Lycopodiaceae). Journal of Pharmacology, 4(492): 36-40.

Ninh Thi Phip, 2013. Techniques for improving vegetative propagation rate of Polyscias fruticosa (L.) Harms. Journal of Science and Development, 11(2): 168-173.

Nong Van Duy, 2015. Situation of research on $H$. serrata in Vietnam. Tay Nguyen Publisher, pp. 7-12.

Qin D.J., Yang Y. K., Xiang J.Q., Zeng F.Z., Li Y.J., Yin H.Q., Zou Y.C., Ma J., 2010. Study on cutting seedling NFT culture technique of Huperzia serrata (Thunb.) Trev. Journal of Hubei University for Nationalities - Natural Science edition, 28(1): 18- 21.

Whittier D.P., Storchova H., 2007. The gametophyte of Huperzia selago in culture. American Fern Journal, 97 (3): 149-154.

Zhang J.C., Zhang H.Y., Ye Z.L., Ye X.H., Zhu M., 2009. Preliminary report of Huperzia serrata nursery constructing and original habitat cutting. Journal of Sanming University, 26(2): 194-198. 